\title{
An Agent-Based Model of Wood Markets: Scenario Analysis
}

\author{
Stefan Holm ${ }^{a b *}$, Oliver Thees ${ }^{a}$, Renato Lemm ${ }^{a}$, Roland Olschewski ${ }^{a}$, Lorenz M. Hilty ${ }^{\text {bc }}$ \\ a Swiss Federal Institute for Forest, Snow and Landscape Research WSL, Zürcherstrasse 111, CH-8903 Birmensdorf, \\ Switzerland.

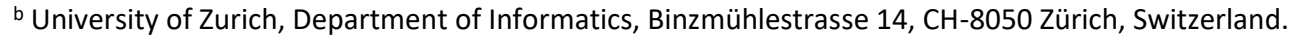 \\ c Empa, Swiss Federal Laboratories for Materials Science and Technology, Lerchenfeldstr. 5, CH-9014 St. Gallen, Switzerland. \\ * Corresponding author, Tel.: +41 44739 2263. Fax: +41 447392215 \\ Email addresses: stefan.holm@wsl.ch, oliver.thees@wsl.ch, renato.lemm@wsl.ch, roland.olschewski@wsl.ch, \\ hilty@ifi.uzh.ch.
}

\begin{abstract}
$\underline{\text { Abstract }}$
We present an agent-based model of wood markets. The model covers softwood and hardwood markets for sawlogs, energy wood, and industrial wood. Our study region is a mountainous area in Switzerland that is close to the border, and therefore partially depends on the wood markets of the adjacent countries. The wood markets in this study region are characterized by many small-scaled wood suppliers, and a mix of private and public-owned forests. The model was developed to investigate the availability of wood in the study region under different market conditions. We defined several scenarios that are relevant to policy makers and analyzed them with a focus on the two most important assortments of wood in the study region, sawlogs softwood and energy wood softwood. The development of the prices and amounts sold in the scenarios are compared to a business-as-usual scenario. The scenarios were designed to investigate i) the influence of intermediaries, ii) the influence of the profit-orientation of forest owners, iii) the influence of the exchange rate, and iv) the consequences of set-asides in the study region. We conclude that the presented model has a large potential to support the planning of political measures as it allows capturing emergent phenomena, and thereby facilitates identifying consequences of political measures planned prior to their implementation.
\end{abstract}

Keywords: Agent-based Modeling, Wood Market, Scenario Analysis, Policy Analysis, Market Simulation, Computer Simulation.

\section{Highlights:}

- We developed a flexible agent-based model of regional wood markets in Switzerland.

- It is adaptable regarding market structure, agent behavior, and policy interventions.

- Economically and politically relevant scenarios were simulated and evaluated.

- The model allows capturing emergent, non-obvious phenomena.

- The model facilitates the analysis of implications of planned political measures.

Funding: This work was supported by the Swiss National Science Foundation [project number: 406640-142933]

This document is the accepted manuscript version of the following article: 


\section{Introduction}

Computer simulation has been an important means in forestry since decades: in the 1960s already, a wide range of topics were modeled and simulated. Amongst others, growth models, forest fire protection models, and harvesting machine simulation models (Newnham, 1968) were developed. Until today, not only the domains of application and modeling purposes have substantially widened, but also the types of simulation techniques applied, making use of the continuously increasing computational power. For example, system dynamics approaches have been used to simulate wood market scenarios (Schwarzbauer \& Stern, 2010) or Monte-Carlo simulations to analyze uncertainties in forest conservation set-aside scenarios (Kallio 2010).

In this paper we present a model of wood markets using the agent-based modeling (ABM) approach. ABM differs from other simulation approaches owing to its bottom-up perspective that allows each agent (in our case, each market participant) to be modeled individually (micro level). Simulating all agents together creates a system behavior due to their interactions. This approach has several advantages, such as the possibility to model the market in a natural and descriptive manner (as an interplay of many autonomous acting agents with different goals) or to capture emergent phenomena on any level of aggregation (macro level) (Bonabeau, 2002; Janssen \& Ostrom, 2006, Macal \& North, 2014). Because of these reasons, ABM is widely used in economics (where it is sometimes referred to as agent-based computational economics, cf. Tesfatsion, 2006): for example, there are many models related to electricity markets (cf. Weidlich \& Veit, 2008). There are even suggestions to model whole economies with the ABM approach (Farmer \& Foley, 2009). In comparison to other simulation approaches, $A B M$ though requires more computational power, which made this method popular only in the recent 10-20 years.

Climate change and derived megatrends, such as energy transition and bio-economy, result in increasing requirements concerning the utilization of forest wood resources. Nevertheless, the sustainable potential of forest wood in Switzerland is currently not used. This situation is strongly related to the market conditions. Considering this background, our model was developed for a better understanding of the markets of forest wood, with a focus on the resource availability and allocation of different assortments. It was the objective to establish an agent-based model and to apply the model to regional wood markets. The study region presented is Grisons in Switzerland, a mountainous region located in the border of Switzerland. In the scenario analysis presented, different market situations were analyzed in terms of their impact on the markets of sawlogs and energy wood.

An explorative study by Kostadinov et al. (2014) showed that agent-based modeling is a suitable method to analyze wood markets, particularly considering the peculiarities of our study region. The new version of that model presented here addresses some important improvements. We solved the model boundary problem, implemented a transport route model which calculates transport costs based on real road and rail routes in the study region, and gathered empirical data on the market participants' decision behavior with discrete choice experiments (Carson \& Louviere, 2011; Louviere et al., 2010) and surveys. Additionally, the conceptual model was extended (more agent types, more markets), a rigorous validation was conducted, and finally the performance of the model was significantly improved, allowing faster scenario simulations with more agents. Details on these improvements are described in Holm et al. (2017). 
Considering the above improvements, the model can now be used for policy analysis by simulating and analyzing politically relevant scenarios. In section 2 , we define a set of such scenarios after providing an overview of the study region and the most important characteristics of the model. Further, we present the variables observed to analyze these scenarios and describe the simulation procedure. Section 3 first presents the results of the scenario simulations on the level of variables observed, then summarizes and discusses these results per scenario, and section 4 concludes the paper.

\section{Material and methods}

In this section, we first describe the study region and the most relevant parts of the model, followed by the simulated scenarios and their relevance to the forest sector in the study region, and finally the observed variables and the simulation procedure.

\subsection{Study Region}

The study region is the canton of Grisons, a mountainous region in eastern Switzerland, located in the border of Austria and Italy. Forestry in Grisons is characterized by a high percentage of public (communal) forests ( $88 \%$ of the total forest size of 195 '494 ha), subsidized protection forests (61\% of the total forest size), and a high percentage of softwood (91\%) (Olschewski et al., 2015). The wood market is characterized by bundling organizations on the supply side. On the demand side, there are small-scale sawmills in Grisons, and larger sawmills in the neighboring Swiss cantons and in the neighboring countries Austria and Italy, to where a high percentage of the wood is exported. The total annual cut is approximately $5001000 \mathrm{~m}^{3}$ and the most important assortment is sawlogs softwood. More detailed information about the study region can be found in Olschewski et al. (2015).

\subsection{Description of the Market Model}

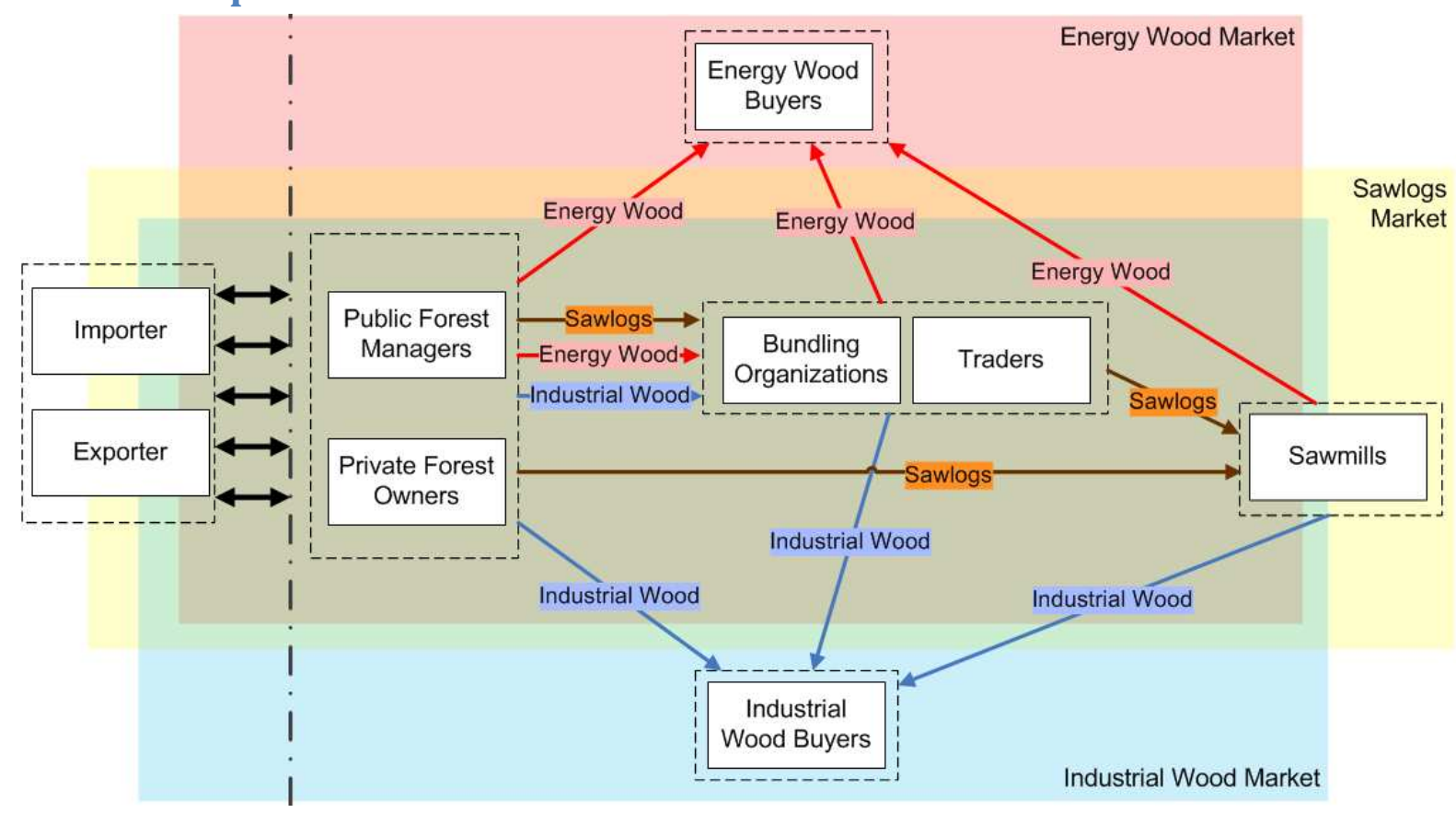

Figure 1: Conceptual model of the markets and the agent types

The model depicts the markets for sawlogs, energy wood, and industrial wood in the canton of Grisons. Figure 1 shows (i) the combined markets of the main products (distinguishing between 
softwood and hardwood) and (ii) the nine different agent types. All the agents have a fixed geographical location, which for public forest managers reflects their real-world position; for other agents, the position is randomly assigned at the beginning of a simulation. A single time step in the model represents one month. In each time step, agents try to negotiate new contracts and/or fulfill their existing ones. A detailed model description according to the ODD/ODD+D protocol (a standardized way to describe agent-based models, Grimm et al., 2006 and 2010; Müller et al., 2013) is available in Holm et al. (2017), where the validation procedure of the model is also described. Therein, a more comprehensive description of the agents, their decision-behavior, their individual goals, and how they interact is provided. For the convenience of the reader, we repeat the agent descriptions as defined in Holm et al. (2017) here:

- Public forest managers: These agents manage the public forests in their area. In our study region, $88 \%$ of the forest is under public ownership (FSO, 2015), which makes them the most important agent group on the supply side of the markets. They sell wood of all six assortments.

- Private forest owners: In our study region, $8 \%$ of the forest is under private ownership (FSO, 2015) (the remaining $3.5 \%$ of the forest in the study region is hybrid property). In absolute numbers, there are 10'110 private forest owners in the study region who own a total forest area of $16^{\prime} 517$ ha (FSO, 2015). With an average size of 1.65 ha per private forest owner, the wood is generally not harvested by the owners themselves, but with the help of public forest managers or contractors. They are often mentored by a public forest manager. In the model, these agents are aggregated such that there is only one private forest owner agent in the territory of each public forest manager, representing (for model simplicity) the aggregate of all private owners in this territory. They sell wood of all six assortments.

- Traders: Traders buy all six wood assortments in the model and try to sell them in the markets at a profit.

- Bundling organizations: These agents are cooperatives of small suppliers (private and public), structured to reduce distribution costs and increase market power. They are modeled as intermediaries who are strongly linked to the affiliated suppliers.

- Sawmills: They buy sawlogs and process them into different wood products (for which the downstream markets are not included in the model). During the processing of sawlogs, residuals (tree bark, woodchips, shavings, and sawdust) are accumulated as byproducts and either used by the sawmill itself or sold on the market as energy wood and industrial wood.

- Industrial wood buyers: They buy industrial wood and process it into products such as pulp and paper. The downstream markets are not included in the model.

- Energy wood buyers: They buy energy wood, predominantly for heating purposes. This includes all consumers from single-family homes with a fireside up to district heating distributors. These market participants are modeled as aggregated agents.

- Importers: They import wood from the outside to the inside of the modeled region.

- Exporters: They export wood from the inside to the outside of the modeled region.

In order to ensure simplicity, the term "forest owners" is used hereafter to represent the wood suppliers, and therefore includes both the public forest managers and private forest owners.

\subsection{Scenario Definition}

Based on a basic wood market situation, we simulated a set of economic and political relevant scenarios to analyze the influence of (i) bundling organizations, (ii) forest managers' profit 
orientation, (iii) exchange rates, and (iv) set-asides, on the supply of forest wood. This selection (i-iv) is the result of workshops with forestry professionals. To facilitate the discussion of the scenarios, they are denominated with a three-letter code.

\subsubsection{Scenario BAU: Business-As-Usual}

A business-as-usual (BAU) scenario is simulated to create a baseline for a comparison with other scenarios. In this scenario, all exogenous variables are fixed: the global wood prices and the exchange rate remain constant, agent quantities do not change (except for sawmills, which continuously exit the market as observed in reality in the past decades), and all model parameters are set to the values for which the model was validated in Holm et al. (2017). This concept of fixing the exogenous variables at the point where the model starts to simulate the future is often called "freezing" in literature (e.g., Hilty et al., 2006; Krewitt et al., 2007; Laitner et al., 2010).

\subsubsection{Scenario BUN: A Market without Bundling Organizations}

On the market under study, we find cooperations of wood suppliers, called "bundling organizations." They aggregate the supply of associated wood suppliers and sell the wood on their behalf. These bundling organizations have sometimes been criticized: forest owners often use bundling organizations only when they are unable to directly sell wood, such as in market situations with low demand. On the other hand, sawmills sometimes view bundling organizations as less reliable partners as they depend on the supply by forest owners, and can also be competitors as both sawmills and bundling organizations want to buy wood. In the BUN-scenario, we remove all bundling organizations from the study region at the beginning of the forest year $2017 / 18$, which is September 1, 2017.

\subsubsection{Scenario DEC: Influence of the Forest Owner's Profit Orientation}

The decision system of the wood suppliers has been implemented on the basis of expert interviews and empirical data from discrete choice experiments. The details of this approach are explained in Holm et al. (2016). When forest owners consider selling sawlogs, they consider four decision criteria: amount of sawlogs available, amount of sawlogs demanded, trust in the demander, and financial margin. Based on the discrete choice experiments, every forest manager has individual decision parameters, and therefore different weights for these decision criteria. Some managers are more profit-oriented, while others, e.g., prefer to sell to customers they have known for years, disregarding small price differences. In this scenario, all forest managers receive new decision parameters in June 2017. These decision parameters reflect a strictly profit-oriented behavior. This scenario is relevant as the sawlogs market in our study region is, according to different expert interviews we conducted, sometimes deemed inefficient as the supply side allegedly does not behave sufficiently profit-oriented.

\subsubsection{Scenario EUR: Influence of the Exchange Rate}

This scenario is divided into two sub-scenarios, EUR080 and EUR150. They start in June 2017 and end in December 2027. During this time period, the exchange rate CHF-EUR is continuously and steadily adapted from 1.093 (the actual exchange rate in June 2017) to $0.80 \mathrm{CHF/EUR} \mathrm{(Scenario} \mathrm{EUR080)} \mathrm{or}$ $1.50 \mathrm{CHF} / \mathrm{EUR}$ (Scenario EUR150). In other words, the exchange rate is reduced by $0.0024 \mathrm{CHF} / \mathrm{EUR}$ per month or increased by $0.0032 \mathrm{CHF} /$ EUR per month in the given time period.

The domestic wood markets, in particular in our study region that is close to the borders of Austria and Italy, are influenced by the exchange rate. Due to the continuous drop of the exchange rate since 2008 (Figure 2), such scenarios became politically relevant, particularly after the interventions of the 
Swiss National Bank (SNB, the central bank of Switzerland) to hold a certain minimum exchange rate, and thereby supporting the export industry, were suddenly stopped.

In September 2011, the SNB announced that "it will no longer tolerate a EUR/CHF exchange rate below the minimum rate of CHF 1.20" and that it "will enforce this minimum rate with the utmost determination and is prepared to buy foreign currency in unlimited quantities" (SNB, 2011). This minimum rate was enforced until January 2015, when the discontinuation of the minimum exchange rate was announced (SNB, 2015). This led to an immediate drop of the exchange rate to 1.00 CHF/EUR (average exchange rate of the day after the discontinuation), recovering slightly in the subsequent weeks, and stabilizing at an exchange rate of approximately 1.05 CHF/EUR (Figure 2). This situation was very challenging for the domestic wood sector as it made the export of wood and wood products very unattractive. It emphasizes the relevance of simulating scenarios related to exchange rate changes. Thereby, the potential impacts on the wood sector can be analyzed in a manner where measures can be planned in advance to absorb potential losses.

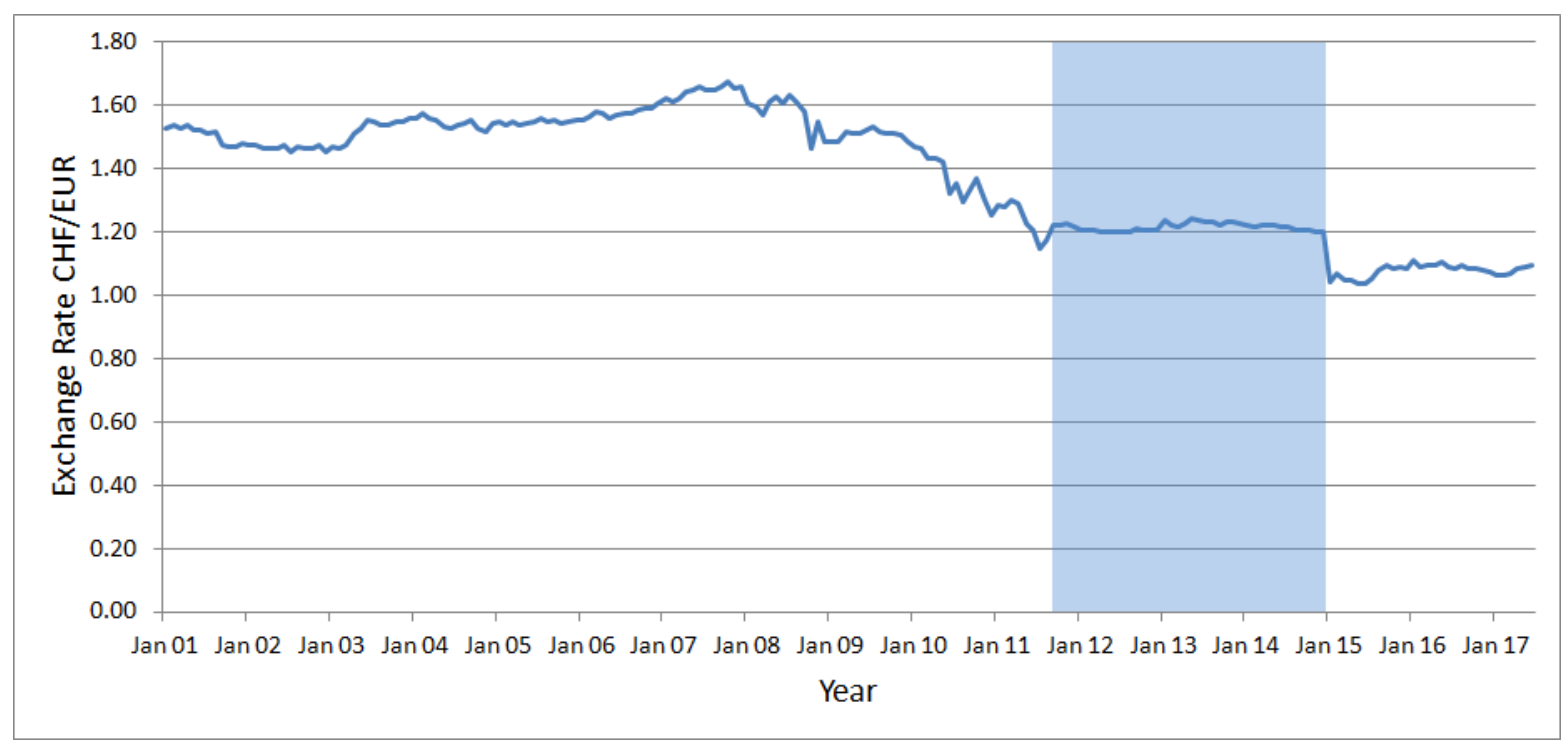

Figure 2: Exchange rate CHF/EUR (monthly averages). The highlighted blue area shows the period of the enforced minimum exchange rate.

\subsubsection{Scenario SET: The Consequences of Set-Asides}

This scenario explores the influence of setting aside forest land, e.g. for conservation purposes, in our study region. What happens if parts of the forest are not managed anymore? Set-asides are already realized in several areas in our study region (AWN, 2017) and also in other parts of Switzerland (Gattlen, 2012). In the simulated scenario, 39\% of the public forests are set aside at the beginning of the forest year $2017 / 18$. This is the maximum as $61 \%$ of the forest area in the study region is protective forest (FOEN, 2016), which cannot be set aside. The scenario is analyzed here only from an economic perspective, not in terms of its ecological effects.

\subsection{Observed Variables}

In Holm et al. (2017), we described how we validated our wood market model. A focus of the model validation was the ability of the model to reproduce historical prices and production amounts. The model depicts the markets of six wood assortments, namely sawlogs (softwood and hardwood), energy wood (softwood and hardwood), and industrial wood (softwood and hardwood). In this paper, we focus on the two most relevant assortments in our study region, sawlogs softwood and 
energy softwood. Together, they account for approximately $93 \%$ of the wood assortments produced in the study region (FSO, 2017).

As the model was able to reproduce historical prices and production amounts to a sufficiently large degree, we also focus on the amounts and prices for scenario evaluation. The following variables are observed in our study region, both for sawlogs and energy wood:

- Amounts sold annually by public forest managers and private forest owners.

- Prices paid by demanders.

- Sales volumes of the two intermediaries in the model, bundling organizations and traders.

In the results section, the development of these variables in the different scenarios are compared and analyzed.

\subsection{Simulation Procedure}

The different phases of our simulations are illustrated in Figure 3: our simulations start in the year 2001 and end in 2027. After the simulation starts, the model requires $2-3$ years to settle down (aspects such as business relationships between agents need to be established). The subsequent simulation period, 2004 to 2016, was used to validate the model (the validation process of the years 2004-2014 is described in Holm et al. (2017)). The scenarios defined above are triggered in the year 2017, as at the time of writing most of the exogenous parameters (e.g., the actual exchange rate) until that year are known, and therefore the scenarios are used for an outlook of 10 years into the future.

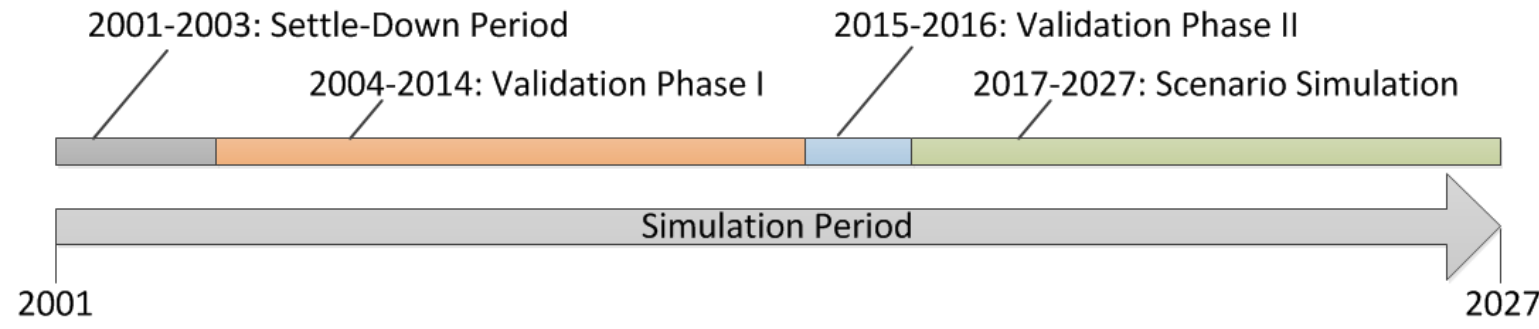

Figure 3: Simulation phases. All scenarios are triggered in 2017 and evaluated for the subsequent 10-year period.

\section{Results and Discussion}

The results presented here are grouped by the observed variables explained in the method section. All the results represent an average of 100 simulation runs as the model is stochastic. All figures in this section represent the amounts sold or prices paid of the agents inside the study region. It is necessary to emphasize this as there are also agents in the model who are located outside the study region and nevertheless interact with the agents inside the study region. This approach is used to avoid boundary effects and is described in detail in Holm et al. (2017). 


\subsection{Sawlogs}

\subsubsection{Prices}

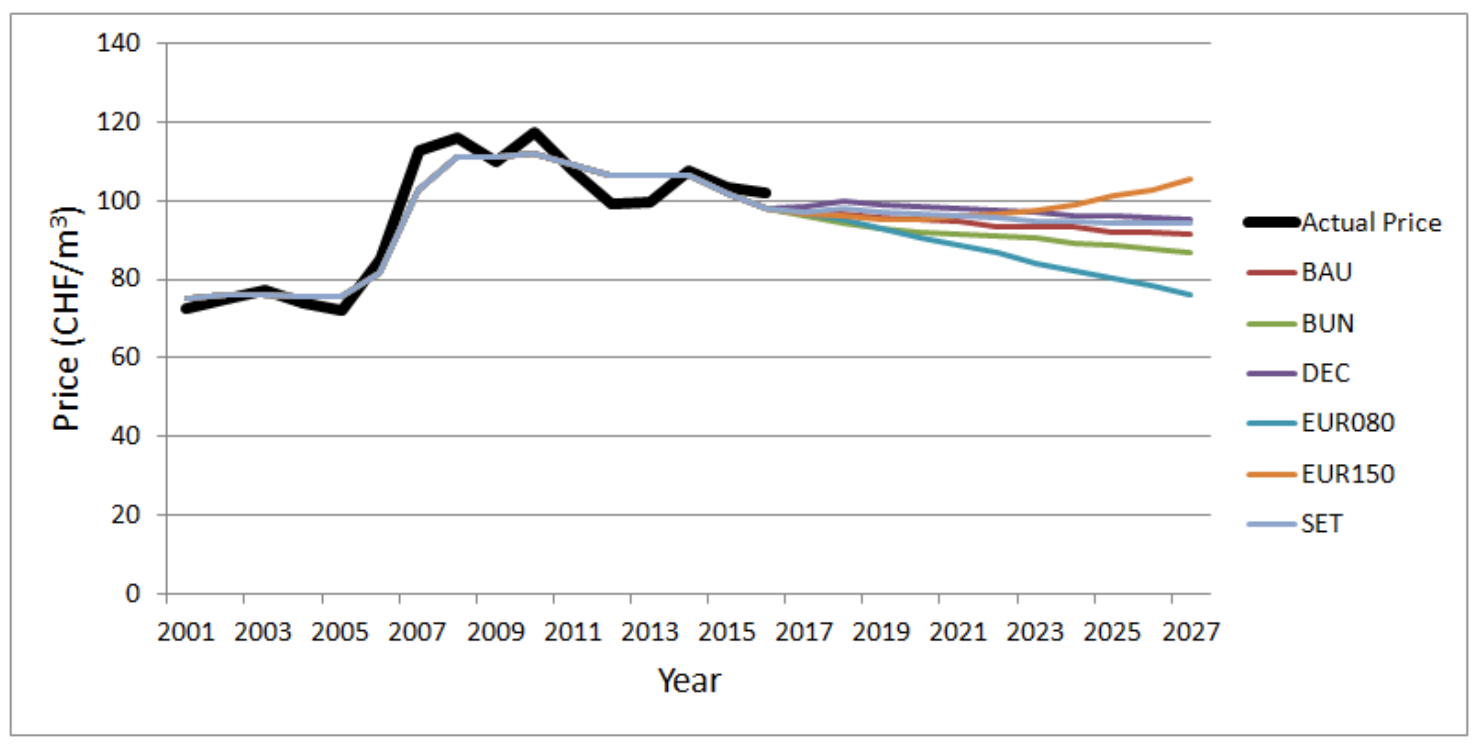

Figure 4: Prices paid for sawlogs (softwood) by sawmills

Figure 4 shows the prices paid for sawlogs (softwood) by sawmills in the study region under different scenarios. The thick black line shows the actual historical prices of sawlogs from 2001 to 2016.

The scenarios leading to the maximal divergences of prices are the two EUR-scenarios. As approximately two thirds of the study region's border is an international border, the wood prices in the study region strongly depend on international wood prices, and on the import and export of wood. Therefore, a lower exchange rate leads to lower local wood prices, and a higher exchange rate results in higher local wood prices. According to the model, the effect of a rising exchange rate is lower in comparison to a decreasing exchange rate. This can be explained by the market power of the demanders: the total demand in the study region is much less in comparison to the total supply.

In the other scenarios, including BAU, the prices slightly drop over the years at a similar rate. However, at the beginning of the scenario simulation in 2017, they divert marginally from each other: the lowest prices appear in the BUN-scenario, marginally higher in the scenarios BAU and SET, and highest in the DEC-scenario. Lower prices in the BUN-scenario can be explained by the provision of 2-5 $\mathrm{CHF} / \mathrm{m}^{3}$ that bundling organizations usually take for their broker-like services. Without bundling organizations, forest owners therefore can retain this provision and sell wood at slightly lower prices (while continuing to not provide the full provision as discount to the demanders, as without bundling organizations, forest owners have to identify buyers themselves, which is challenging under conditions of a "buyer's market"). Prices in the SET-scenario are approximately $2 \%$ higher in comparison to the BAU-scenario, which can be explained by the reduction of supply, and thereby less competition between the suppliers. Even higher prices appear in the DEC-scenario, where they are approximately $3.5-4 \%$ higher in comparison to the BAU-scenario. A stronger profit-orientation of forest owners in this scenario leads to these higher prices.

Why do the scenarios BAU, BUN, DEC, and SET only divert in 2017/18, and afterwards the curves remain approximately parallel? The scenarios BUN, DEC, and SET all start in 2017, i.e. at that time exogenous model variables were changed. After this change, there is a short phase where the agents adapt themselves to the new situation. In this short period of time, the four scenarios diverge. 
Subsequently, there are no more changes of exogenous variables, and therefore the curves remain approximately parallel.

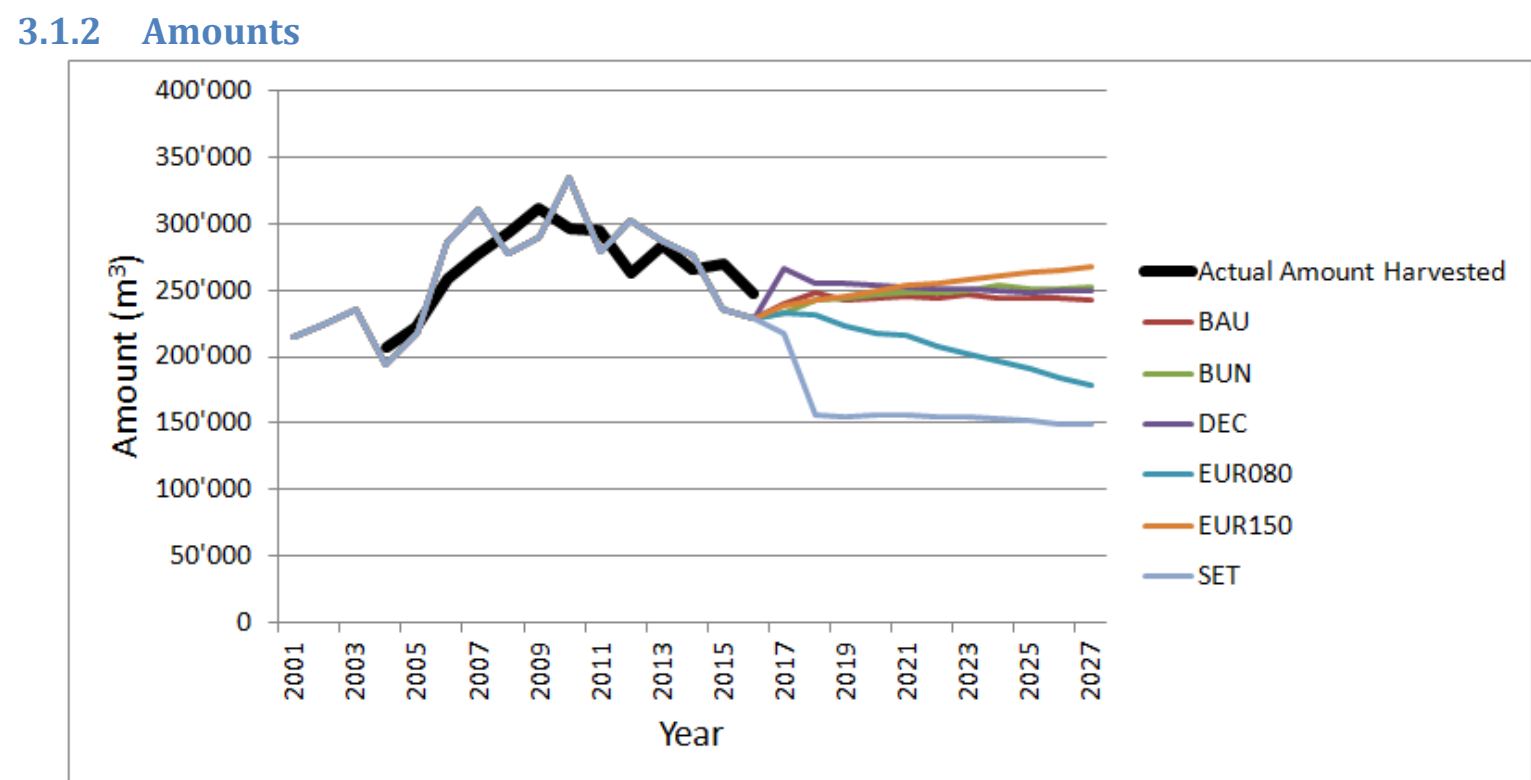

Figure 5: Amount of sawlogs (softwood) sold by forest owner

Figure 5 shows the amounts of sawlogs (softwood) sold by public forest managers and private forest owners in the study region. The thick black line shows the actual historical values of harvested sawlogs from 2004 to 2016. Harvested and sold amounts of sawlogs are generally equalized in the long run. The small differences in the individual years can be explained by the time between harvesting and selling (sawlogs are generally stocked in the forest between 1 and 6 months), and annual cut off.

In the BAU-scenario, the annual amount of sawlogs sold remains constant over the years (after the triggering of the scenarios in 2017). The largest divergences are observed in the EUR-scenarios and the SET-scenario: a higher exchange rate leads to higher amounts sold, a lower one to lower amounts sold. The impact of a lower exchange rate is stronger than the one of a higher exchange rate: if forest owners are forced to lower their prices, they harvest less wood. On the other hand, even with increasing prices, forest owners are not able to immediately sell much more wood as they do not have the capacity for it. In the SET-scenario, where $39 \%$ of the public forest is set aside on September 1,2017 , the sold amount unsurprisingly drops by $39 \%$. In the scenarios BUN and DEC, the amounts sold are approximately 3-4\% higher than in the BAU-scenario. Considering the BUN-scenario, this can again be explained by the fact that a bundling organization generally takes 2 to $5 \mathrm{CHF}$ (approx. 25 USD) as provision. If forest owners are not required to pay this provision, they can retain a part of the provision for themselves and pass on the other part to the buyer by selling at lower prices. In this manner, the seller gets more money and the buyer pays less, which leads to more sawlogs being sold by forest owners. Considering the DEC-scenario, the increase in the amounts sold can be explained by higher prices for the forest owners as well. 


\subsubsection{Intermediaries}
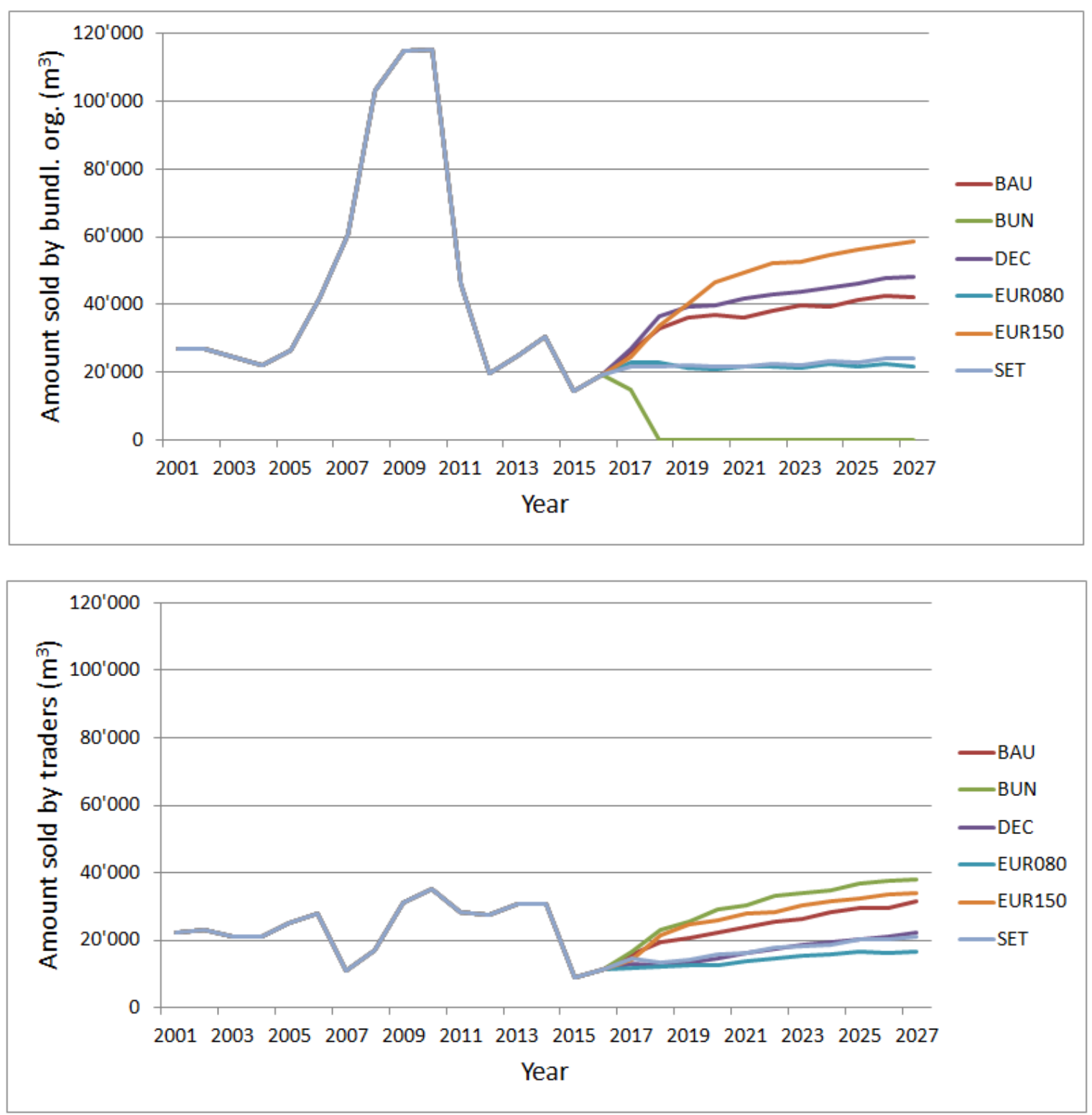

Figure 6: Amount of sawlogs sold by bundling organizations (top diagram) and traders (bottom diagram) in the different scenarios

Figure 6 shows the amount of sawlogs sold by intermediaries in the study region. For this data, the actual historical values are unknown. The remarkable peak between 2007 and 2010 for the wood sold by bundling organizations can be explained by a bulk consumer who was active in the study region during that time period (in the municipality Domat/Ems) (Suedostschweiz, 2015), who presumably bought a significant amount of wood from bundling organizations. Bundling organizations sell wood as soon as they have a demander and one or several suppliers who they can "connect." Therefore, they do not have the risk of having a stock that is hardly sellable. However, traders buy and sell "at their own expense," which could be the reason why they profited less from the bulk consumer who was a strong market player (and was considered over-sized from many market actors and indeed became insolvent in 2010) (Suedostschweiz, 2015). A second remarkable anomaly before the scenarios start is the significant drop of amounts sold by both bundling organizations and traders in 2015. In January 2015, the exchange rate of CHF-EUR dropped by approximately $15 \%$ (cf. description of EUR-Scenario). This immediately led to a massive reduction of 
amounts sold. In 2016 already, the amounts sold increased again, converging to the former level after several years.

Observing the various developments of the amounts sold by bundling organizations in the scenarios, the strongest rise of amounts sold can be observed in the EUR150-scenario, which is obviously a consequence of the increasing amounts of wood sold by forest owners. The same explanation applies for the DEC-scenario, where the amounts are slightly higher than in the BAU-scenario. The scenarios EUR080 and SET interestingly lead to very similar amounts sold. This can be interpreted from a bundling organization's point of view that setting aside 39\% of the public forests or a constant decrease of the exchange rate of $0.0288 \mathrm{CHF} / \mathrm{EUR}$ annually has the same consequences in terms of amounts sold.

Considering traders, the amounts sold rise in all the scenarios, as explained above. The intensity of the rise differs, particularly in the first years of the scenarios. In the BUN-scenario, the increase is the strongest as traders are now the only intermediaries in the market. The second strongest increase can be observed in the EUR150-scenario, followed by the BAU-scenario. The increases in the scenarios DEC and SET are much weaker and not considerably different from the EURO80-scenario.

There are two further remarkable observations. The first is the difference of amounts sold between bundling organizations and traders in the DEC-scenario in comparison to the respective BAUscenario. Bundling organizations sell in the DEC-scenario more than in the BAU-scenario, traders sell less than in the BAU-scenario, which means that profit-oriented forest owners prefer bundling organizations over traders as intermediaries. The second observation is that the SET-scenario has the same consequences as the EUR080-scenario for bundling organizations, while for the traders, the consequences of set-asides are not as intense as the consequences of the EURO80-scenario. This can be explained by the strong link between bundling organization and forest owners, which results in bundling organizations being more affected by set-asides in comparison to traders.

\subsection{Energy Wood}

\subsubsection{Prices}

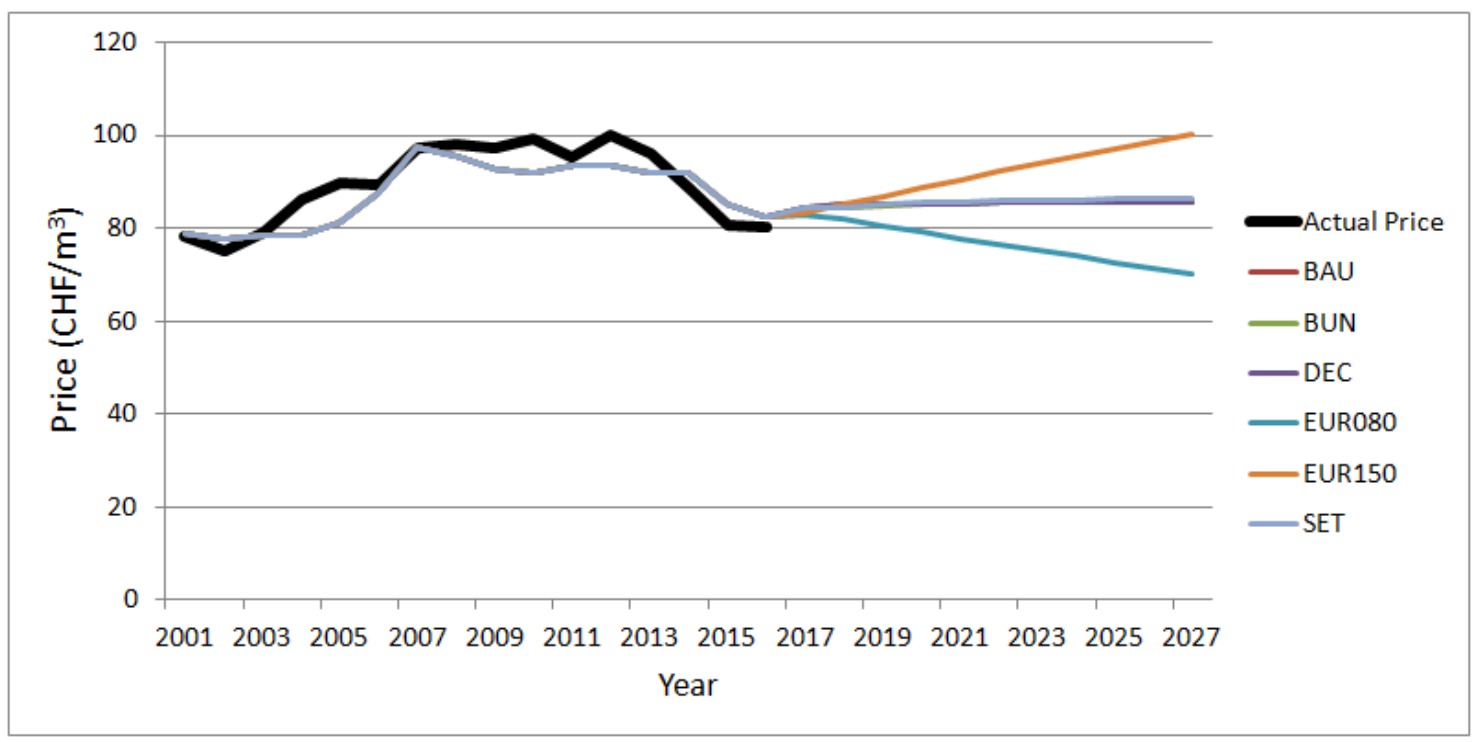

Figure 7: Prices paid for energy wood by energy wood consumers. The prices in the scenarios BAU, BUN, DEC, and SET are almost equal, and therefore overlap in the diagram. 
Figure 7 shows the prices paid for energy wood (softwood) by energy wood consumers in the study region under different scenarios. The thick black line shows the actual historical prices of energy wood from 2001 to 2016.

The EUR-scenarios have a strong influence on the energy wood prices, while in other scenarios, the price development is almost equal. A very small difference can be observed in the SET-scenario, where prices in 2027 are approximately $1 \%$ higher than in the other scenarios. This can be explained by the reduction of supply, which leads to less competition.

The reason that the price development for the scenarios BAU, BUN, and DEC is almost equal, is that they mainly influence the sawlogs market. The DEC-scenario only changes the decision parameters of forest owners when they sell sawlogs as this is the main product which triggers the harvesting process. In the BUN-scenario, the provisions previously paid to the bundling organizations are now retained by the forest owners and not passed on to the customers, such as those in the sawlogs market.

\subsubsection{Amounts}

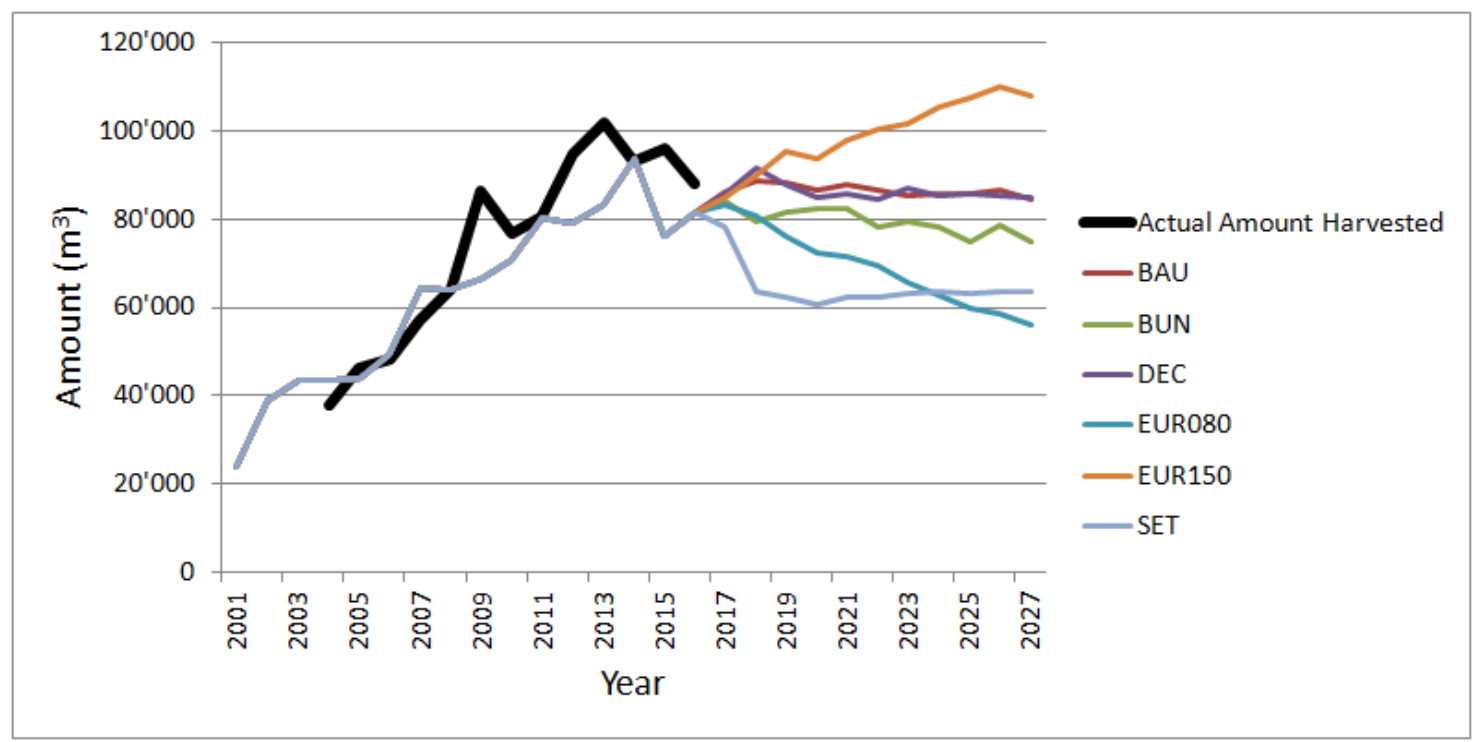

Figure 8: Amount of energy wood sold by forest owners

Figure 8 shows the amount of energy wood (softwood) sold by forest owners in the study region. The thick black line shows the actual historical values of produced energy wood from 2004 to 2016 . The amounts of energy wood produced and sold are generally equalized in the long run. The small differences in the individual years can be explained by the time between harvesting and selling (energy wood can be stocked up to 2 years in the forest without loss of quality) and annual cut off.

The amount of energy wood sold in the scenarios BAU and DEC show almost equal and constant quantities in time. As previously explained for energy wood prices, the DEC-scenario only influences the decision parameters of forest owners selling sawlogs; therefore, there is no influence on the energy wood market.

In the two EUR-scenarios, the sold amounts rise/drop according to the prices of energy wood.

In the SET-scenario, the sold amounts first drop by almost the same percentage as the percentage of public forests that are set aside, before they start to rise again slightly. This can be explained by the 
price difference between sawlogs and energy wood. The prices of sawlogs slightly decrease in the scenarios BAU and SET, while the price for energy wood remains almost constant. This leads to a small shift of the percentage of a tree that is used for sawlogs and for energy wood, more toward energy wood.

In the BUN-scenario, forest owners sell approximately $10 \%$ less energy wood in comparison to the BAU-scenario. This can be interpreted as bundling organizations providing valuable support in finding demanders for energy wood.

\subsubsection{Intermediaries}
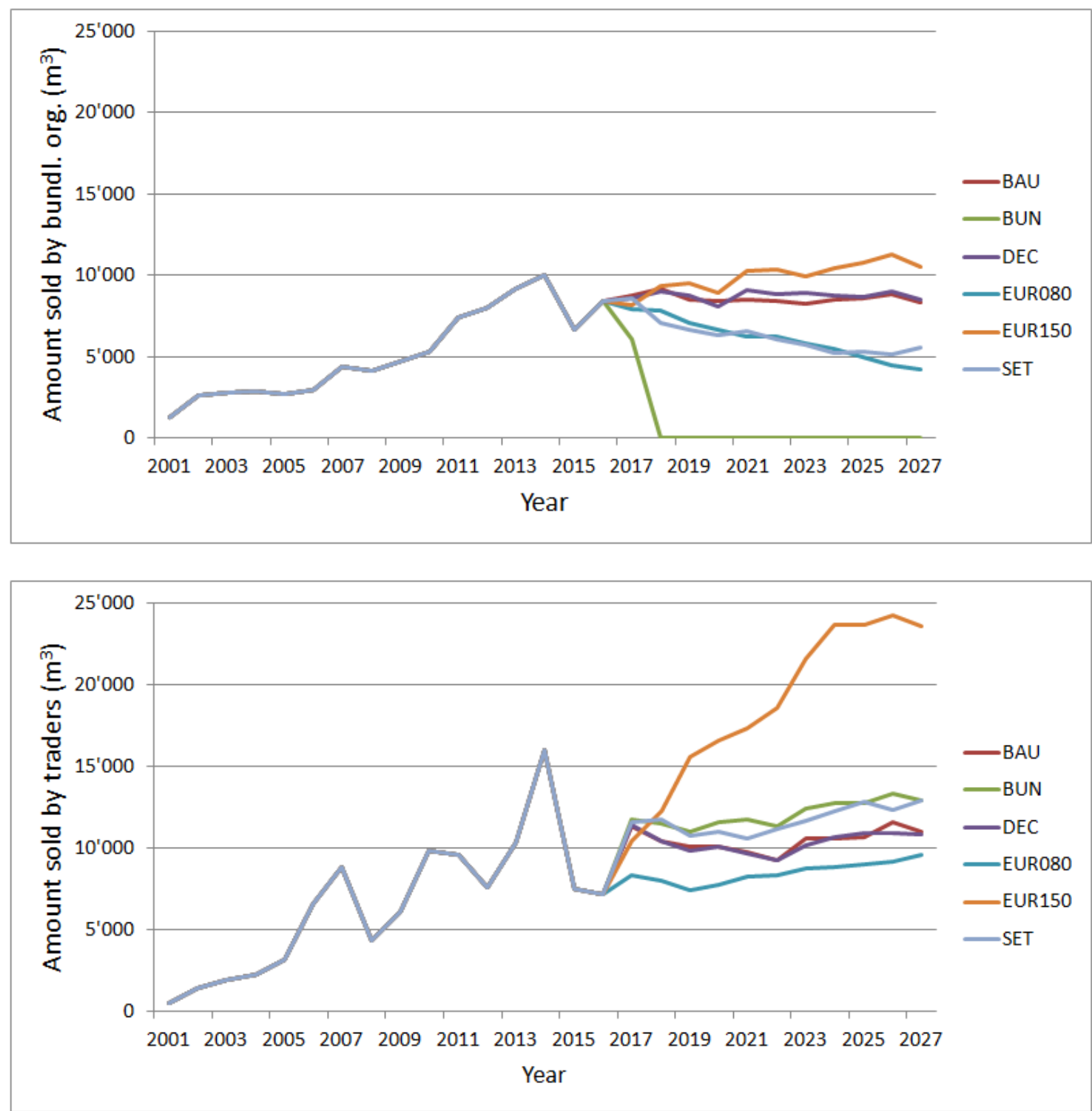

Figure 9: Amount of energy wood sold by bundling organizations (top diagram) and traders (bottom diagram) in the different scenarios

Figure 9 shows the amount of energy wood sold by intermediaries in the study region. For this data, the actual historical values are unknown. Until the scenarios start, the development of the variable is similar for bundling organizations and traders, with traders showing marginally higher amounts and more distinct peaks in comparison to bundling organizations. The amounts sold clearly increase until 2014 and show a short drop in 2015, when the exchange rate significantly dropped. This is in 
accordance with the amounts sold by forest owners in the study region, from which the intermediaries buy their wood.

After the start of the scenarios in 2017 , the scenarios BAU and DEC show approximately constant quantities, both for bundling organizations and traders. The reasons for the similar developments of BAU and DEC concerning energy wood were mentioned above (section 3.2.2).

The BUN-scenario provides traders approximately $20 \%$ higher sales or $2000 \mathrm{~m}^{3}$ more in absolute terms. In 2017, before the bundling organizations disappeared, they sold approximately $8000 \mathrm{~m}^{3}$ annually. Therefore, traders were not able to overtake the complete amount from the other type of intermediary. This complies with the observation on the amount sold by forest owners in the BUNscenario in Figure 8 , where bundling organizations provide valuable support in finding demanders for energy wood, apparently much more than traders.

The EUR-scenarios have the same consequences for bundling organizations as for forest owners: sold amounts rise or fall similarly for both agent types. Traders profit much more from an increasing exchange rate, and even a decreasing exchange rate has only a low impact on the amount of energy wood sold by traders. This can be clarified by the following observations: when the exchange rate increases, almost all energy wood that is additionally sold by the forest owners goes to the traders who then export it, which explains the high increase in traders' sales. When the exchange rate decreases, the forest owners sell a higher percentage of their wood to traders, which explains why traders are less affected in this scenario in comparison to bundling organizations.

The SET-scenario has different effects for bundling organizations and for traders. For bundling organizations, the set-asides lead to a decrease in sales, similar to the EUR080-scenario; however, for the traders, this leads to an increase of sales of approximately $20 \%$. Bundling organizations buy only from forest owners; therefore, they directly depend on the total size of managed forests. Traders profit from the set-asides and achieve an increase in energy wood sold. It can be observed that the remaining public forest managers proportionally sell less energy wood to bundling organizations and more to traders. The explanation for this is that due to the reduction of supply from public forests, bundling organizations are challenged to bundle sufficient amounts of energy wood, as there are less suppliers though the same number of bundling organizations. Another interpretation would be that traders start to import wood to counterbalance the loss of domestic supply. Thoroughly analyzing the model output though reveals that import of energy wood is almost nonexistent. This can be explained by the relatively high transportation costs of energy wood and the fact that the domestic supply of energy wood even in this scenario is still sufficient to satisfy the domestic energy wood demanders.

\subsection{Summary of Scenario Findings}

In the previous sections, we presented the results of the scenario simulations by interpreting the various variables observed. In this section, we summarize these results by discussing them holistically, per scenario rather than per variable.

The BAU-scenario shows approximately constant values for most variables, except for the prices of sawlogs, which slightly decrease, and the amounts of sawlogs sold by intermediaries, which first strongly rise back to their level before the historical drop of the exchange rate and then continue with a slight but continuous increase. The slight decrease in prices can be explained by the fact that sawmills in the study region are disappearing over the years. These market exits have been occurring 
since several decades in the study region (FSO, 2013). The consequence is a reduction of demand which leads to lower prices. The continuous disappearing of sawmills also makes export more important as sawmills and exporters are the only demanders in the sawlogs market. This makes the intermediaries focus on delivering to exporters, which slightly shifts the market shares of exported wood from forest owners toward intermediaries.

The absence of bundling organizations in the BUN-scenario leads to slightly lower sawlogs prices, which reflects the absence of the provision previously taken by the bundling organizations. However, bundling organizations took the provision for a service, which forest owners now have to undertake themselves. Considering the energy wood market, forest owners have profited from this service, as without bundling organizations, they are unable to continue to sell the same amount of energy wood. Traders can profit in both the markets as they are now the only intermediaries in the markets.

The DEC-scenario only influences the sawlogs market: both prices and the amount sold by forest owners are approximately 3-4\% higher in comparison to the BAU-scenario. The more profit-oriented forest owners in this scenario prefer bundling organizations over traders as intermediaries, which increases the amount sold by bundling organizations by $10 \%-15 \%$, and decreases the amount sold by traders by approximately $30 \%$.

The EUR-scenarios have a strong influence on all the variables observed. A higher exchange rate leads to higher prices and higher sales, while a lower exchange rate leads to lower prices and lower sales. However, the extent of increasing or decreasing sales is sometimes different: considering the energy wood market, traders profit more from an increasing exchange rate than bundling organizations, and they are also less affected by a decreasing exchange rate.

The SET-scenario, where $39 \%$ of the public forests are set aside, leads to slightly higher sawlogs prices $(+2 \%)$. Considering sawlogs sales, it affects bundling organizations $(-40 \%$ sales) more than traders (-30\% sales) as bundling organizations buy their wood only directly from forest owners. Prices in the energy wood market are not affected. The amount of energy wood sold by forest owners and bundling organizations decreases, traders profit from that situation and sell $10-20 \%$ more.

\section{Conclusions}

We presented a model of the wood markets in a study region in Switzerland. The model, which was validated with empirical data from multiple sources (Holm et al., 2017), is adjustable regarding market structure, agent behavior, and policy interventions. We simulated and analyzed several scenarios relevant to stakeholders and policy makers, and showed that the model delivers reasonable results that can be used to draw conclusions back to the real system.

While the model provides the exact numbers to certain questions, such as what is the rate at which the price of sawlogs changes if $39 \%$ of the public forests are set-aside, these numbers have to be interpreted with care before political decisions are made that will affect the real system. A careful interpretation includes explaining the results by analyzing causal mechanisms that lead to a change in an observed variable. It has to be checked which causal mechanisms are involved, and also which ones are not. It has to be evaluated if these causal mechanisms are realistic, and if the intensity of such mechanisms in the real world is similar to those in the model. Attention must be paid to not interpret the results by considering causal mechanisms that could exist in reality but are not actually modeled. For example, price fixing can explain some phenomena observed in the scenarios, but as 
there is no price fixing between agents in the model, this is not a causal mechanism that is allowed for the interpretation of the results (price fixing in fact plays a negligible role in the market modeled here, and was therefore omitted in the model). Finally, the accuracy of the assumptions for the BAUscenario need to be judged as the size of the impact of a scenario depends on the baseline assumed in the BAU-scenario (cf. Hilty et al., 2014). Considering that these steps were thoroughly conducted, the model can be a helpful instrument to conduct experiments in silico and thereby identifying the consequences of discussed political measures prior to their implementation. The nature of agentbased models allows capturing of emerging phenomena, i.e. phenomena that result from the interaction of the agents, and that are often not obvious or even counterintuitive (Bonabeau, 2002). Therefore, we conclude that the presented model has a large potential to support planning of political measures concerning the wood markets under study.

\section{Acknowledgements}

This work is part of the project "An economic analysis of Swiss wood markets," which is funded by the Swiss National Science Foundation through its National Research Program "Resource Wood" (NRP 66).

\section{References}

AWN (Amt für Wald und Naturgefahren). (2017). Naturvorrangflächen [Nature priority areas]. Retrieved November 27, 2017, from: https://www.gr.ch/DE/institutionen/verwaltung/bvfd/awn/wald/3_4_waldoekologie/naturschutz/Se iten/3_4_3_3_naturvorrangflaechen.aspx.

Bonabeau, E. (2002). Agent-based modeling: Methods and techniques for simulating human systems. Proceedings of the National Academy of Sciences, 99(suppl 3), 7280-7287.

Carson, R. T., \& Louviere, J. J. (2011). A common nomenclature for stated preference elicitation approaches. Environmental and Resource Economics, 49(4), 539-559.

Farmer, J. D., \& Foley, D. (2009). The economy needs agent-based modelling. Nature, 460(7256), 685686.

FOEN (Federal Office for the Environment) (2016). Jahrbuch Wald und Holz 2016 [Yearbook Forest and Wood, 2016]. Bundesamt für Umwelt [Federal Office for the Environment], Bern, Switzerland.

FSO (Swiss Federal Statistical Office) (2013). Strukturveränderungen in den Schweizer Sägewerken, 1996-2012 [Structural changes in Swiss sawmills, 1996-2012]. Switzerland

FSO (Swiss Federal Statistical Office) (2015). Forstflächen nach Eigentümertyp und Kantonen, 2014 [Forest areas according to owner type and cantons, 2014]. Switzerland.

FSO (Swiss Federal Statistical Office) (2017). Holzernte der Schweiz in $\mathrm{m}^{3}$ nach Jahr, Kanton, Eigentümertyp und Holzartengruppe [Wood harvest in Switzerland according to year, canton, owner and wood type]. Schweizerische Forststatistik [Swiss Forest Statistics]. Bundesamt für Statistik [Swiss Federal Statistical Office], Neuchâtel, Switzerland. 
Gattlen, N. (2012). Waldreservate für 20000 Arten [Forest preserves for 20'000 species]. Artenvielfalt umwelt 3/2012:39-43.

Grimm, V., Berger, U., Bastiansen, F., Eliassen, S., Ginot, V., Giske, J., Goss-Custard, J., Grand, T., Heinz, S.K., Huse, G., Huth, A., Jepsen, J.U., Jørgensen, C., Mooij, W.M., Müller, B., Pe'er, G., Piou, C., Railsback, S.F., Robbins, A.M., Robbins, M.M., Rossmanith, E., Rüger, N., Strand, E., Souissi, S., Stillman, R.A., Vabø, R., Visser, U. \& DeAngelis, D.L. (2006). A standard protocol for describing individual-based and agent-based models. Ecological Modelling, 198(1-2):115-126. doi:10.1016/j.ecolmodel.2006.04.023.

Grimm, V., Berger, U., DeAngelis, D.L., Polhill, J.G., Giske, J. \& Railsback, S.F. (2010). The ODD protocol: A review and first update. Ecological Modelling, 221(23):2760-2768. doi:10.1016/j.ecolmodel.2010.08.019.

Hilty, L. M., Aebischer, B. \& Rizzoli, A. E. (2014). Modeling and evaluating the sustainability of smart solutions. Environmental Modelling \& Software, 56, 1-5. doi:10.1016/j.envsoft.2014.04.001

Hilty, L. M., Arnfalk, P., Erdmann, L., Goodman, J., Lehmann, M., \& Wäger, P. A. (2006). The relevance of information and communication technologies for environmental sustainability-a prospective simulation study. Environmental Modelling \& Software, 21(11), 1618-1629.

Holm, S., Lemm, R., Thees, O., \& Hilty, L.M. (2016). Enhancing Agent-based Models with Discrete Choice Experiments. Journal of Artificial Societies and Social Simulation, 19(3), 3. doi: 10.18564/jasss.3121

Holm, S., Hilty, L.M., Lemm, R., \& Thees, O. (2017). Empirical Validation of an Agent-Based Model of Wood Markets. Submitted to PLOS ONE, minor revisions pending.

Janssen, M. A., \& Ostrom, E. (2006). Empirically based, agent-based models. Ecology and Society, 11(2), 37.

Kallio, A. M. I. (2010). Accounting for uncertainty in a forest sector model using Monte Carlo simulation. Forest Policy and Economics, 12(1), 9-16.

Kostadinov, F., Holm, S., Steubing, B., Thees, O. \& Lemm, R. (2014). Simulation of a Swiss wood fuel and roundwood market: An explorative study in agent-based modeling. Forest Policy and Economics, 38: 105-118. doi:10.1016/j.forpol.2013.08.001

Krewitt, W., Simon, S., Graus, W., Teske, S., Zervos, A., \& Schäfer, O. (2007). The $2^{\circ}$ C scenario-a sustainable world energy perspective. Energy Policy, 35(10), 4969-4980.

Laitner, J. A., Knight, C. P., McKinney, V. L., \& Ehrhardt-Martinez, K. (2010). Semiconductor technologies: The potential to revolutionize US energy productivity (Part III). Environmental Quality Management, 19(4), 29-50.

Louviere, J. J., Flynn, T. N., \& Carson, R. T. (2010). Discrete choice experiments are not conjoint analysis. Journal of Choice Modelling, 3(3), 57-72.

Macal, C., \& North, M. (2014). Introductory tutorial: Agent-based modeling and simulation. In Proceedings of the 2014 Winter Simulation Conference (pp. 6-20). IEEE Press. 
Müller, B., Bohn, F., Dreßler, G., Groeneveld, J., Klassert, C., Martin, R., Schlüter, M., Schulze, J., Weise \& H., Schwarz, N. (2013). Describing human decisions in agent-based models - ODD + D, an extension of the ODD protocol. Environmental Modelling \& Software, 48, 37-48. doi:10.1016/j.envsoft.2013.06.003.

Newnham, R. M. (1968). Simulation models in forest management and harvesting. The Forestry Chronicle, 44(1), 7-13.

Olschewski, R., Schaller, M., Dittgen, A., Lemm, R., Kimmich, C., Markovic, J., \& Thees, O. (2015). Marktverhalten öffentlicher Forstbetriebe in Graubünden und im Aargau [Market behavior of public forest enterprises in the cantons Graubünden and Aargau]. Schweizerische Zeitschrift für Forstwesen [Swiss Forestry Journal], 166(5), 282-290. https://doi.org/10.3188/szf.2015.0282

Schwarzbauer, P., \& Stern, T. (2010). Energy vs. material: Economic impacts of a "wood-for-energy scenario" on the forest-based sector in Austria-A simulation approach. Forest Policy and Economics, 12(1), 31-38

SNB (2011). Swiss National Bank sets minimum exchange rate at CHF 1.20 per euro. Swiss National Bank, Zurich. https://www.snb.ch/en/mmr/reference/pre 20110906/source/pre 20110906.en.pdf

SNB (2015). Swiss National Bank discontinues minimum exchange rate and lowers interest rate to 0.75\%. Swiss National Bank, Zurich. https://www.snb.ch/en/mmr/reference/pre 20150115/source/pre 20150115.en.pdf

Suedostschweiz (2015). Das Areal der Grosssägerei im Zeitraffer [The area of the large sawmill in time lapse]. Retrieved November 26, 2017, from: https://www.suedostschweiz.ch/wirtschaft/201510-21/das-areal-der-grosssagerei-im-zeitraffer. Archived at: http://www.webcitation.org/6vGa6c6KH

Tesfatsion, L. (2006). Agent-based computational economics: A constructive approach to economic theory. Handbook of computational economics, 2, 831-880.

Weidlich, A., \& Veit, D. (2008). A critical survey of agent-based wholesale electricity market models. Energy Economics, 30(4), 1728-1759. 